\title{
Prevalence, risk factors, phenotypic and molecular characteristics for Staphylococcus aureus carriage in community-based drug users in Guangzhou, China
}

Yingying Wang ${ }^{1+}$, Jialing Lin ${ }^{2+}$, Junli Zhou ${ }^{1}$, Zhigang $\operatorname{Han}^{3^{*}}$ and Zhenjiang Yao ${ }^{1 *}$ (D)

\begin{abstract}
Background: Staphylococcus aureus (S. aureus), particularly methicillin-resistant Staphylococcus aureus (MRSA), remains the predominant cause of infections in drug users. This cross-sectional study aims to elucidate the prevalence, risk factors, phenotypic and molecular characteristics of $S$. aureus carriage among community-based drug users.

Methods: All eligible drug users, with both injection and non-injection route of drug administration, were asked to complete questionnaires and collect nasal swabs by trained personal during the period between May and December 2017 in Guangzhou, China. Swabs were processed for identification of S. aureus. Antimicrobial susceptibility test and polymerase chain reaction assays were used to detect phenotypic and molecular characteristics for identified isolates. Univariate and multivariate logistic regression analyses were used to assess risk factors for $S$. aureus carriage.

Results: Overall, 353 drug users were included in the study and the prevalence of S. aureus carriage was 15.01\% (53/353). The prevalence of MRSA carriage was 6.80\% (24/353). Cohabitation was a risk factor for S. aureus (adjusted $\mathrm{OR}=8.80,95 \% \mathrm{Cl}: 1.89-40.99$ ). The proportion of multidrug resistance was $54.72 \%$ for $\mathrm{S}$. aureus isolates and most of these isolates were resistant to penicillin, erythromycin and clindamycin. Seventeen MRSA isolates were multidrug resistant. The results of clonal complexes (CCS) and sequence types (STs) for S. aureus were diverse. The three predominant types for CCs were CC5 $(64.15 \%, 34 / 53)$, CC59 $(11.32 \%, 6 / 53)$, and CC7 $(7.55 \%, 4 / 53)$; and for STs were ST188 (20.75\%, 11/53), ST5 (11.32\%, 6/53), and ST59 (11.32\%, 6/53).

Conclusion: The prevalence of $\mathrm{S}$. aureus nasal carriage was lower while the prevalence of MRSA carriage was moderate compared to previous studies. Phenotypic and molecular characteristics of S. aureus isolates, particularly MRSA isolates, revealed high proportions of antibiotic resistance, indicating the existence of cross-circulation, and implying high opportunity of virulence-related diseases. Decolonization and antibiotic stewardship might be implemented for drug users with MRSA carriage.
\end{abstract}

Keywords: S. aureus, MRSA, Risk factor, Antimicrobial susceptibility, Drug user, Molecular characteristics

\footnotetext{
* Correspondence: 863833728@qq.com; zhjyao2001@yahoo.com

†Yingying Wang and Jialing Lin contributed equally to this work.

${ }^{3}$ Department of AIDS/STD Control and Prevention, Guangzhou Center for

Disease Control and Prevention, Guangzhou 510310, China

${ }^{1}$ Department of Epidemiology and Health Statistics, Guangdong

Pharmaceutical University, Guangzhou 510310, China

Full list of author information is available at the end of the article
}

(c) The Author(s). 2020 Open Access This article is distributed under the terms of the Creative Commons Attribution 4.0 International License (http://creativecommons.org/licenses/by/4.0/), which permits unrestricted use, distribution, and reproduction in any medium, provided you give appropriate credit to the original author(s) and the source, provide a link to the Creative Commons license, and indicate if changes were made. The Creative Commons Public Domain Dedication waiver (http://creativecommons.org/publicdomain/zero/1.0/) applies to the data made available in this article, unless otherwise stated. 


\section{Background}

Staphylococcus aureus (S. aureus), particularly methicillin-resistant $S$. aureus (MRSA), continues to be a major pathogen in both hospital- and communityassociated infections [1]. It has been reported that nasal carriers of $S$. aureus have an increased risk of being infected by this pathogen [2].

Based on the latest World Drug Report, an estimated 271 million people aged 15-64 used drugs, with both injection and non-injection route of drug administration and 35 million people were estimated to be suffering from drug use disorders in 2017 [3]. Obviously, illicit drug use is a global public health problem. In recent studies, the prevalence of $S$. aureus, particularly MRSA carriage, among drug users is higher compared to the general population $[4,5]$. The phenotypic and molecular characteristics of $S$. aureus isolates in drug users were little reported. Most of these studies were conducted in developed countries, including the United States of America, Canada, and European countries. There is no similar work conducted among drug users in China.

According to the above facts, it is necessary to investigate the epidemiology of $S$. aureus carriage, particularly MRSA carriage, among drug users, in China. Therefore, in this study, we aimed to elucidate the prevalence, risk factors, phenotypic and molecular characteristics of $S$. aureus from the nasal cavity of community-based drug users in Guangzhou, China.

\section{Methods}

\section{Ethics statement}

The study was approved by the Ethics Committee of Guangdong Pharmaceutical University, and it was performed in accordance with the approved guidelines. Written informed consent were obtained from all participants.

\section{Study design and participants}

A cross-sectional study of $S$. aureus nasal carriage among all drug users, with both injection and noninjection route of drug administration, was conducted between May and December 2017 in three community health service centers, Guangzhou, China. Participants who had used drug in the previous 12 months were voluntarily recruited in the study. Drugs included opiates, heroin, methamphetamine (methamphetamine), morphine, marijuana, cocaine, and other addictive narcotic drugs and psychotropic substances. Those participants with psychiatric illness or acute diseases were excluded. A face-to-face questionnaire was used to collect relevant information, including demographics (age, sex), sociorelated characteristics (employment status, living conditions, income levels, history of homelessness, and history of incarceration), behavior (history of sex and the number of sexual partners), health-related characteristics (human immunodeficiency virus (HIV) status, hepatitis, antibiotic use, skin infection, hospitalization, and history of needle exchange), and periods, and route of drug use. In this study, cohabitation refers to someone living together with another person without marriage.

\section{Isolation and identification of S. aureus}

After completing the questionnaire part of the study, trained personnel collected swabs from both anterior nares of the participants. The swabs were soaked in $7.5 \%$ sodium chloride broth at $4{ }^{\circ} \mathrm{C}$ during transportation, and then incubated at $37 \pm 1^{\circ} \mathrm{C}$ for $24 \mathrm{~h}$ for further experiments. The swabs were used to inoculate mannitol salt agar for 24-48 h incubation. Samples were identified as $S$. aureus isolates when they had specific colony morphology and were positive for gram staining, catalase reaction, hemolysis test, DNase test, coagulase tests, and $16 S$ rRNA and nuc genes. Two colonies were picked from one mannitol plate. Those $S$. aureus isolates that were resistant to cefoxitin and/or positive for mecA gene were identified as MRSA isolates, all other S. aureus isolates were identified as methicillin-sensitive $S$. aureus (MSSA). More details were described in the previous work [6].

\section{Phenotypic characterization}

The antimicrobial susceptibility of all $S$. aureus isolates was determined by the disk diffusion method, following the guidelines of the Clinical and Laboratory Standards Institute of 2015. The following antibiotics were tested: clindamycin, erythromycin, penicillin, linezolid, gentamicin, teicoplanin, moxifloxacin, trimethoprimsulfamethoxazole, rifampin, chloramphenicol, and tetracycline. The reference S. aureus strain ATCC 25923 and ATCC 29213 were used for quality and positive control. We classified the isolates as susceptible and resistant to each antibiotic. Those isolates resistant to $\geq 1$ agent in $\geq 3$ antimicrobial categories were identified as multidrug resistant (MDR) [7]. More details were described in previous work [6].

\section{Molecular characterization}

All S. aureus isolates were also tested for the carriage of tetracycline-resistant genes $[\operatorname{tet}(\mathrm{M}), \operatorname{tet}(\mathrm{K})]$ and erythromycin-resistant genes $[\operatorname{erm}(\mathrm{A}), \operatorname{erm}(\mathrm{C})]$. All $S$. aureus isolates were further tested to confirm the presence of toxin genes including Panton-Valentine leukocidin genes ( $l u k F-P V$ and $l u k S-P V)$, Toxic shock syndrome toxin-1 gene (tst), Exfoliative toxin A gene (eta), Exfoliative toxin B gene (etb) and Staphylococcal enterotoxins (SEs) (sea-see, seg-ser, seu) genes. Multilocus sequence typing (MLST) was performed to confirm clonal complexes (CCs) and sequence types (STs). Additionally, all MRSA isolates were tested for Staphylococcal cassette 
chromosome mec (SCCmec) typing. More details were described in previous work [6].

\section{Statistical analysis}

The data were entered using Epidata 3.1 (EpiData Association, Odense Denmark) and exported to Stata 14.2 (College Station, Texas, USA) software for further analysis. We assessed the associations between $S$. aureus carriers and relevant characteristics by the following methods. Univariate analyses were conducted using the Pearson's chi-squared test or the Fisher's exact test when appropriate. Multivariate logistic regression models were used to determine risk factors associated with S. aureus carriage. Independent risk factors with a $P<0.1$ in univariable logistic regression analysis were included in the multivariable models. Potential confounding covariates were adjusted in the models. A twosided $P$-value of $\leq 0.05$ was defined as statistical significance.

\section{Results}

Prevalence of $S$. aureus carriage

A total of 353 drug users were eligible for inclusion in the study. The prevalence of $S$. aureus nasal carriage in drug users was $15.01 \%(53 / 353)$. The prevalence of MRSA carriage was $6.80 \%(24 / 353)$.

\section{Risk factors of $S$. aureus carriage}

Table 1 shows univariate analyses of $S$. aureus carriage among drug users. After adjusting for confounding covariaes, current cohabitation was still a risk factor for $S$. aureus carriage $(\mathrm{aOR}=8.80,95 \% \mathrm{CI}: 1.89-40.99)$ in drug users (Fig. 1).

\section{Phenotypic characteristics}

The antibiotic susceptibility testing results revealed that most $S$. aureus isolates were susceptible to linezolid, rifampin and gentamicin, but resistant to penicillin (92.45\%), erythromycin (49.06\%), clindamycin (45.28\%) and tetracycline (32.08\%) (Table 2). Eighteen S. aureus isolates were MDR. Notably, $38.89 \%$ of MDR S. aureus were resistant to erythromycin, clindamycin and chloramphenicol. For MRSA isolates, the proportion of MDR MRSA was $36.00 \%$ (9/24) (Fig. 2). The proportions of antibiotic resistance were higher in MRSA isolates than MSSA isolates (Table 2).

Table 1 Univariate analysis of risk factor for S. aureus carriage among drug users in Guangzhou, China, 2017

\begin{tabular}{|c|c|c|c|}
\hline Characteristics & Non-S. aureus carriage $(N=300)$ & S. aureus carriage $(N=53)$ & $P$-value \\
\hline \multicolumn{4}{|l|}{ Demographics-level } \\
\hline Sex (Male) & $262(87.33)$ & $47(88.68)$ & 0.784 \\
\hline age $(>50)$ & $169(56.33)$ & $26(49.06)$ & 0.326 \\
\hline \multicolumn{4}{|l|}{ Social-level } \\
\hline Current employed (Yes) & $80(26.67)$ & $14(26.42)$ & 0.970 \\
\hline Current cohabitataion (Yes) & $3(1.00)$ & $4(7.55)$ & 0.011 \\
\hline Low income (Yes) & $61(20.33)$ & $17(32.08)$ & 0.058 \\
\hline History of homelessness in past 6 months (Yes) & $9(3.00)$ & $3(5.66)$ & 0.400 \\
\hline History of incarceration (Yes) & $240(80.00)$ & $44(83.02)$ & 0.609 \\
\hline \multicolumn{4}{|l|}{ Behavior-level } \\
\hline History of vaginal sex in past 1 month (Yes) & $97(33.68)$ & $13(26.53)$ & 0.324 \\
\hline Number of sexual partners in past 1 year $(>1)$ & $28(9.33)$ & $2(3.77)$ & 0.283 \\
\hline \multicolumn{4}{|l|}{ Health-level } \\
\hline Current HIV positive (Yes) & $22(7.33)$ & $2(3.77)$ & 0.553 \\
\hline Current hepatitis (Yes) & $114(38.00)$ & $24(45.28)$ & 0.316 \\
\hline Antibiotic use in past 6 months (Yes) & $83(27.67)$ & $16(30.19)$ & 0.706 \\
\hline History of hospitalization in past 1 year (Yes) & $32(10.67)$ & $9(16.98)$ & 0.186 \\
\hline History of skin infection in past 6 months (Yes) & $130(43.33)$ & $25(47.17)$ & 0.604 \\
\hline History of needle exchange in past 1 year (Yes) & $26(8.67)$ & $4(7.55)$ & 1.000 \\
\hline \multicolumn{4}{|l|}{ Drug use-level } \\
\hline Period of drug use (> 10 years) & $18(6.00)$ & $0(0.00)$ & 0.087 \\
\hline History of heroin snorting in past 3 months (Yes) & $188(62.67)$ & $41(77.36)$ & 0.039 \\
\hline History of intravenous heroin in past 3 months (Yes) & $113(37.67)$ & $14(26.42)$ & 0.116 \\
\hline History of using injection drugs in past 3 months (Yes) & 187 (62.33) & 39 (73.58) & 0.116 \\
\hline
\end{tabular}

S. aureus Staphylococcus aureus; N Number of total participants; HIV Human immunodeficiency virus 


\begin{tabular}{|c|c|c|c|c|c|}
\hline Characteristic & Non-S. aureus carriage & S. aureus carriage & Adjusted OR $(95 \% \mathrm{CI})$ & & \\
\hline Current cohabitation (Yes) & $4(7.55)$ & $3(1.00)$ & $8.80(1.89-40.99)$ & & $\longrightarrow$ \\
\hline Low income (Yes) & $17(32.08)$ & $61(20.33)$ & $0.49(0.25-0.96)$ & & \\
\hline History of homelessness in previous 6 months (Yes) & $3(5.66)$ & $9(3.00)$ & $2.00(0.52-7.67)$ & & \\
\hline History of incarceration (Yes) & $44(83.02)$ & $240(80.00)$ & $0.84(0.39-1.82)$ & & \\
\hline History of vaginal sex in previous 1 month (Yes) & $13(26.53)$ & $97(33.68)$ & $1.42(0.72-2.80)$ & & \\
\hline Current HIV positive (Yes) & $2(3.77)$ & $22(7.33)$ & $2.11(0.48-9.33)$ & $\mapsto$ & \\
\hline History of hospitalization in previous 1 year (Yes) & $9(16.98)$ & $32(10.67)$ & $0.56(0.25-1.27)$ & & \\
\hline History of skin infection in previous 6 months (Yes) & $25(47.17)$ & $130(43.33)$ & $0.84(0.47-1.51)$ & & \\
\hline \multirow[t]{2}{*}{ History of heroin snorting in previous 3 months (Yes) } & $12(22.64)$ & $112(37.33)$ & $0.48(0.24-0.95)$ & & \\
\hline & & & 0.01 & 1.00 & 100.00 \\
\hline
\end{tabular}

Fig. 1 Multivariate analysis of risk factors for S. aureus carriage among community-based drug users in Guangzhou, China, 2017. S. aureus, Staphylococcus aureus; No., Number of; OR, Odds ratio; Cl, Confidence interval; HIV, Human immunodeficiency virus

In terms of macrolide-resistant genes, five (9.43\%) $S$. aureus isolates were positive for the $\operatorname{erm}(\mathrm{C})$ and one (1.89\%) was positive for the erm(A) gene. Only one $S$. aureus isolate was positive for both the $\operatorname{erm}(\mathrm{C})$ and erm(A) genes. For tetracycline-resistant genes, four (7.55\%) S. aureus isolates were positive for the tet $(\mathrm{K})$ and no isolate was positive for tet $(\mathrm{M})$ gene. Additionally, only one $S$. aureus isolate was positive for $\operatorname{erm}(\mathrm{C})$, $\operatorname{erm}(\mathrm{A})$ and tet $(\mathrm{K})$ genes. These gene-positive $S$. aureus isolates were all MRSA isolates.

\section{Molecular characteristics}

Overall, 8 CCs and 18 STs were detected from 53 S. aureus isolates (Fig. 2). Three of the most predominant CCs were CC5 (34), CC59 (6), and CC7 (4). Three of the most predominant STs were ST188 (11), ST5 (6), and ST59 (6). For 24 MRSA isolates, 7 CCs and 13 STs were detected. Two of the most predominant CCs were CC5 (13) and CC59 (6). Two of the most predominant STs were ST188 (6) and ST59 (6).

In terms of virulence genes (Table 2), 5.66\% of $S$. aureus isolates were positive to $l u k F-P V$ and $l u k S-P V$ genes. Two MRSA isolates were positive to the tst gene. Notably, only one MRSA isolate was positive to the eta gene and one to the $e t b$ gene. For the SEs genes, the three most predominant genes were seg (49.06\%), sei (34.96\%) and sad (32.08\%). All S. aureus isolates were negative to the sea and see genes.

A total of four SCCmec types were detected from the 24 MRSA isolates, in which 12 isolates were type IVd, five were type IVa, one was type V, one was type II, and five were non-typeable (Fig. 2).

\section{Discussion}

To the best of our knowledge, this is a relatively comprehensive study which contributes to the understanding of the prevalence, risk factors, phenotypic and molecular characteristics for $S$. aureus nasal carriage among community-based drug users in China. The prevalence of $S$. aureus carriage in the study (15.01\%) is lower than previously reported estimates which ranged from 19.79 to $45.05 \%$ [4, 8-11]. Participants of those previous studies were injection drug users. In this study, however, only $64.02 \%$ of participants had history of using injection drugs in the past 3 months. Additionally, we found that a majority of long-term drug users who took drugs by snorting had few vibrissae. This might also be a potential factor leading to a low prevalence of $S$. aureus carriage, further studies about the impact of snorting drugs on S. aureus carriage need to be conducted in the future The prevalence of MRSA nasal carriage $(6.80 \%)$ in the study is similar to the previous studies in other countries [4, 12-14], but higher than that in the general population in China [15]. Additionally, the proportion of MRSA in S. aureus isolates was higher than the observed studies $[4,14]$.

In this study, we found that current cohabitation might be a risk factor for $S$. aureus carriage in drug users, which is different from another study [4]. One of the possible reasons might be that most drug users cohabitated with other drug users. This could provide more opportunities for sharing drugs [11]. HIV infection has been reported to be a risk factor for S. aureus carriage [16], however, we did not find any significance in this study. This could be caused by the limited number of drug users with HIV infection. Therefore, further studies need to be carried out to identify the risk factors for $S$. aureus carriage in drug users.

The patterns of antibiotic resistance on $S$. aureus isolates are consistent with limited available studies $[8,17$, 18], with high proportions of penicillin, erythromycin, clindamycin and tetracycline resistance. The proportions of antibiotic resistance were higher in MRSA isolates than MSSA isolates, which is also observed in other studies [8, 18]. Teicoplanin has been widely used as an anti-MRSA agent in infectious patients in the past decades [19, 20], which can partially explain the high proportion of 
Table 2 Phenotypic and molecular characteristics of S. aureus isolates among drug users in Guangzhou, China, 2017

\begin{tabular}{|c|c|c|c|}
\hline \multirow[t]{2}{*}{ Characteristics } & \multicolumn{3}{|c|}{ S. aureus $(N=53)$} \\
\hline & Total & $\operatorname{MRSA}(N=24)$ & MSSA $(N=29)$ \\
\hline \multicolumn{4}{|l|}{ Resistant phenotype (resistant) } \\
\hline Clindamycin & $24(45.28)$ & $15(62.50)$ & $9(31.03)$ \\
\hline Erythromycin & $26(49.06)$ & $15(62.50)$ & $11(37.93)$ \\
\hline Penicillin & $49(92.45)$ & $23(95.83)$ & $26(89.66)$ \\
\hline Linezolid & $1(1.89)$ & $1(4.17)$ & $0(0.00)$ \\
\hline Gentamicin & $4(7.55)$ & $3(12.50)$ & $1(3.45)$ \\
\hline Teicoplanin & $10(18.87)$ & $8(33.33)$ & $2(6.90)$ \\
\hline Trimethoprim-sulfamethoxazole & $7(13.21)$ & $4(16.67)$ & $3(10.34)$ \\
\hline Moxifloxacin & $5(9.43)$ & $4(16.67)$ & $1(3.45)$ \\
\hline Rifampin & $2(3.77)$ & $2(8.33)$ & $0(0.00)$ \\
\hline Chloramphenicol & $11(20.75)$ & $7(29.17)$ & $4(13.79)$ \\
\hline Tetracycline & $17(32.08)$ & $9(37.50)$ & $8(27.59)$ \\
\hline \multicolumn{4}{|l|}{ Resistant genotype (positive) } \\
\hline $\operatorname{erm}(A)$ & $1(1.89)$ & $1(4.17)$ & $0(0.00)$ \\
\hline $\operatorname{erm}(\mathrm{C})$ & $5(9.43)$ & $5(20.83)$ & $0(0.00)$ \\
\hline $\operatorname{tet}(\mathrm{K})$ & $4(7.55)$ & $4(16.67)$ & $0(0.00)$ \\
\hline $\operatorname{tet}(\mathrm{M})$ & $0(0.00)$ & $0(0.00)$ & $0(0.00)$ \\
\hline \multicolumn{4}{|l|}{ Virulence genes (positive) } \\
\hline lukF-PV and lukS-PV & $3(5.66)$ & $3(12.50)$ & $0(0.00)$ \\
\hline tst & $2(3.77)$ & $2(8.33)$ & $0(0.00)$ \\
\hline eta & $1(1.89)$ & $1(4.17)$ & $0(0.00)$ \\
\hline etb & $1(1.89)$ & $1(4.17)$ & $0(0.00)$ \\
\hline sea & $0(0.00)$ & $0(0.00)$ & $0(0.00)$ \\
\hline seb & $1(1.89)$ & $0(0.00)$ & $1(3.45)$ \\
\hline $\mathrm{sec}$ & $3(5.66)$ & $1(4.17)$ & $2(6.90)$ \\
\hline sed & $17(32.08)$ & $11(45.83)$ & 6 (20.69) \\
\hline see & $0(0.00)$ & $0(0.00)$ & $0(0.00)$ \\
\hline seg & $26(49.06)$ & $13(54.17)$ & $13(44.83)$ \\
\hline seh & $3(3.45)$ & $3(12.50)$ & $0(0.00)$ \\
\hline sei & 18 (33.96) & $9(37.50)$ & $9(31.03)$ \\
\hline sej & $6(11.32)$ & $3(12.50)$ & $3(10.34)$ \\
\hline sek & $11(20.75)$ & 8 (33.33) & $3(10.34)$ \\
\hline sel & $4(7.55)$ & $2(8.33)$ & $2(6.90)$ \\
\hline sem & $16(30.19)$ & $6(25.00)$ & $10(34.48)$ \\
\hline sen & $12(22.64)$ & $4(16.67)$ & 8 (27.59) \\
\hline seo & $13(24.53)$ & $4(16.67)$ & $9(31.03)$ \\
\hline sep & $4(7.55)$ & $1(4.17)$ & $3(10.34)$ \\
\hline seq & $5(9.43)$ & $2(8.33)$ & $3(10.34)$ \\
\hline ser & $5(9.43)$ & $2(8.33)$ & $3(10.34)$ \\
\hline seu & $12(22.64)$ & $7(29.17)$ & $5(17.24)$ \\
\hline
\end{tabular}

S. aureus Staphylococcus aureus; MRSA Methicillin-resistant S. aureus; MSSA Methicillin- sensitive S. aureus 


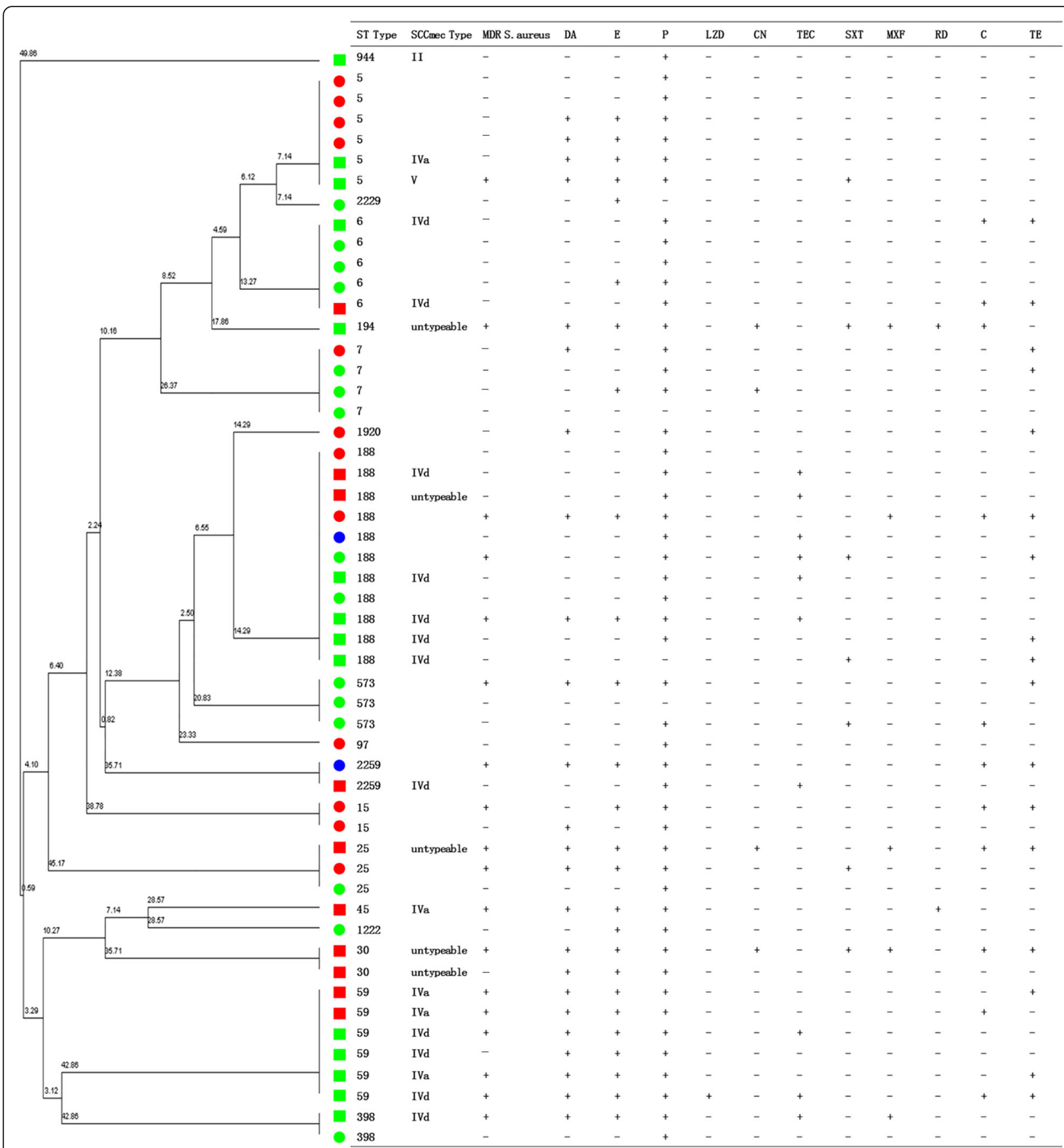

Fig. 2 Clonal dendrogram and detailed information of S. aureus isolates for community-based drug users in Guangzhou, China, 2017. Isolates with the same color represented they were from the same community; squares represented MRSA isolates and circles represented MSSA isolates. S. aureus, Staphylococcus aureus; MRSA, Methicillin-resistant S. aureus; MSSA, Methicillin- sensitive S. aureus; ST, Sequence type; SCCmec, Staphylococcal cassette chromosome mec; MDR, Multidrug resistance; P, Penicillin; E, Erythromycin; DA, Clindamycin; TE, Tetracycline; C, Chloramphenicol; SXT, Trimethoprim-sulfamethoxazole; TEC, Teicoplanin; MXF, Moxifloxacin; CN, Gentamicin; RD, Rifampin; LZD, Linezolid

teicoplanin resistance in MRSA isolates. The most predominant MDR pattern of S. aureus isolates could partially demonstrate the high use of antibiotics in community-based drug users and provide evidence that healthcare workers need to be more careful with selection of antibiotics for drug users. Therefore, the administration of antibiotics for drug users should be strengthened.

The proportions of virulence genes were high in MRSA, suggesting the higher risks of MRSA isolates in causing virulence-related diseases, including Staphylococcal 
scalded skin syndrome, toxic shock syndrome, Staphylococcal food poisoning, etc. [21-23]. The proportions of virulence genes for MRSA isolates were higher than the observed studies [6, 24-26]. The results implied that drug users with MRSA carriage harboring virulence associated genes, might have higher risks for relevant disease and should draw more attention.

We found high proportions of ST5 and ST59 in this study and these STs were also globally reported in communities [27]. We also found hospital- (ST188) [28, 29] and livestock- (ST398) [30, 31] associated STs in this study. The results of CCs and STs for S. aureus isolates could demonstrate the multiple transmissions among human beings, livestock and environment, which are similar to previous studies $[6,24]$. According to the results of SCCmec types, we could know the source of MRSA isolates might be both communities and healthcare settings, which is similar to the observed studies [4, 9]. Additionally, we found some $S$. aureus isolates displayed identical molecular characteristics, suggesting the possibility of cross-transmission between the communities and healthcare settings and this might be a potential risk for other populations. Relevant decolonization methods could be taken for drug users with MRSA carriage, which would help prevent further MRSA circulation [32].

Our study contributes to the understanding of the prevalence, risk factors, phenotypic and molecular characteristics for $S$. aureus carriage, particularly MRSA carriage, among drug users in China. Despite the strengths of this study, there are several limitations. First, it was a crosssectional study. Thus, we could not determine the persistence of $S$. aureus carriage. Secondly, we only collected nasal swabs instead of nasopharyngeal swabs, which may lead to underestimation of the prevalence of $S$. aureus carriage. Thirdly, we did not collect information whether male participants were those who have sex with men due to confidentiality. We will explore it in future research. Finally, the generality of this study is limited owing to the small number of drug users.

\section{Conclusion}

In summary, the prevalence of $S$. aureus nasal carriage was lower, while the prevalence of MRSA nasal carriage was moderate among community-based drug users but higher than that of general population in China. Cohabitation is a risk factor for S. aureus carriage. Phenotypic and molecular characteristics of MRSA isolates reveal serious antibiotic resistance, indicate the crosscirculation of MRSA isolates between communities and healthcare settings, and imply high opportunity of virulence-related diseases. Decolonization and antibiotic stewardship might be implemented for drug users with MRSA carriage, especially for those with risk factors.

\section{Abbreviations}

aOR: Adjusted odds ratio; C: Chloramphenicol; CC: Clonal complex;

Cl: Confidence interval; CN: Gentamicin; DA: Clindamycin; E: Erythromycin; HIV: Human immunodeficiency virus; LZD: Linezolid; MDR: Multidrug resistance; MLST: Multilocus sequence typing; MRSA: Methicillin-resistant S. aureus; MSSA: Methicillin- sensitive S. aureus; MXF: Moxifloxacin; P: Penicillin; RD: Rifampin; S. aureus: Staphylococcus aureus; SCCmec: Staphylococcal cassette chromosome mec; SE: Staphylococcal enterotoxin; ST: Sequence type; SXT: Trimethoprim-sulfamethoxazole; TE: Tetracycline; TEC: Teicoplanin

\section{Acknowledgements \\ Not applicable.}

\section{Authors' contributions}

$W Y$ and $J$ performed the experiments, participated in data analysis and contributed to manuscript writing. JZ collected information, performed the experiments, and analyzed the results. $Z Y$ and $Z H$ designed the study and critically reviewed the manuscript. All authors revised the manuscript and approved the final form.

\section{Funding}

This study was supported by the Guangdong Science and Technology Planning Project (Grant number 2014A020213013). The funders had no role in study design, data collection and analysis, decision to publish or preparation of the manuscript.

\section{Availability of data and materials}

the data supporting the conclusions of this manuscript will be made available by the corresponding authors to any qualified researcher

\section{Ethics approval and consent to participate}

The study was approved by the Ethics Committee of Guangdong Pharmaceutical University, and it was performed in accordance with the approved guidelines. Written informed consent were obtained from all participants.

\section{Consent for publication}

Not applicable.

\section{Competing interests}

The authors declare that they have no competing interests.

\section{Author details}

${ }^{1}$ Department of Epidemiology and Health Statistics, Guangdong Pharmaceutical University, Guangzhou 510310, China. ${ }^{2}$ School of Public Health and Community Medicine, The University of New South Wales, Sydney, NSW, Australia. ${ }^{3}$ Department of AIDS/STD Control and Prevention, Guangzhou Center for Disease Control and Prevention, Guangzhou 510310, China.

Received: 30 November 2019 Accepted: 7 February 2020

Published online: 02 March 2020

\section{References}

1. Paterson GK, Harrison EM, Holmes MA. The emergence of mecC methicillinresistant Staphylococcus aureus. Trends Microbiol. 2014;22:42-7.

2. Wertheim HF, Melles DC, Vos MC, van Leeuwen W, van Belkum A, Verbrugh $H A$, Nouwen JL. The role of nasal carriage in Staphylococcus aureus infections. Lancet Infect Dis. 2005;5:751-62.

3. World drug report 2019. https://wdr.unodc.org/wdr2019/prelaunch/prelaunchpresentation_WDR_2019.pdf.

4. Leung NS, Padgett P, Robinson DA, Brown EL. Prevalence and behavioural risk factors of Staphylococcus aureus nasal colonization in communitybased injection drug users. Epidemiol Infect. 2015;143:2430-9.

5. El-Sharif A, Ashour HM. Community-acquired methicillin-resistant Staphylococcus aureus (CA-MRSA) colonization and infection in intravenous and inhalational opiate drug abusers. Exp Biol Med (Maywood). 2008;233: 874-80.

6. Lin J, Liang J, Zhang T, Bai C, Ye J, Yao Z. Dose-response associations of methicillin-resistant Staphylococcus aureus between school environmental 
contamination and nasal carriage by elementary students. Infect Drug Resist. 2018;11:773-82.

7. Magiorakos AP, Srinivasan A, Carey RB, Carmeli Y, Falagas ME, Giske CG, Harbarth S, Hindler JF, Kahlmeter G, Olsson-Liljequist B, et al. Multidrugresistant, extensively drug-resistant and pandrug-resistant bacteria: an international expert proposal for interim standard definitions for acquired resistance. Clin Microbiol Infect. 2012;18:268-81.

8. Al-Rawahi GN, Schreader AG, Porter SD, Roscoe DL, Gustafson R, Bryce EA. Methicillin-resistant Staphylococcus aureus nasal carriage among injection drug users: six years later. J Clin Microbiol. 2008:46:477-9.

9. Gwizdala RA, Miller M, Bhat M, Vavagiakis P, Henry C, Neaigus A, Shi Q, Lowy FD. Staphylococcus aureus colonization and infection among drug users: identification of hidden networks. Am J Public Health. 2011; 101:1268-76.

10. Bassetti S, Wolfisberg L, Jaussi B, Frei R, Kuntze MF, Battegay M, Widmer AF. Carriage of Staphylococcus aureus among injection drug users: lower prevalence in an injection heroin maintenance program than in an oral methadone program. Infect Control Hosp Epidemiol. 2004;25:133-7.

11. Quagliarello B, Cespedes C, Miller M, Toro A, Vavagiakis P, Klein RS, Lowy FD. Strains of Staphylococcus aureus obtained from drug-use networks are closely linked. Clin Infect Dis. 2002;35:671-7.

12. Miller M, Cespedes C, Vavagiakis P, Klein RS, Lowy FD. Staphylococcus aureus colonization in a community sample of HIV-infected and HIVuninfected drug users. Eur J Clin Microbiol Infect Dis. 2003;22:463-9.

13. Fleisch $F$, Zbinden $R$, Vanoli $C$, Ruef $C$. Epidemic spread of a single clone of methicillin-resistant Staphylococcus aureus among injection drug users in Zurich, Switzerland. Clin Infect Dis. 2001;32:581-6.

14. Dahlman D, Jalalvand F, Blome MA, Hakansson A, Janson H, Quick S, Nilsson AC. High Perineal and overall frequency of Staphylococcus aureus in people who inject drugs, compared to non-injectors. Curr Microbiol. 2017;74:159-67

15. Chen B, Dai X, He B, Pan K, Li H, Liu X, Bao Y, Lao W, Wu X, Yao Y, Huang S. Differences in Staphylococcus aureus nasal carriage and molecular characteristics among community residents and healthcare workers at Sun Yat-Sen University, Guangzhou, Southern China. BMC Infect Dis. 2015;15:303.

16. Ganesh R, Castle D, McGibbon D, Phillips I, Bradbeer C. Staphylococcal carriage and HIV infection. Lancet. 1989;2:558.

17. Fleisch F, Oechslin EC, Gujer AR, Ritzler E, Imhof A, Ruef C, Reinhart WH. Transregional spread of a single clone of methicillin-resistant Staphylococcus aureus between groups of drug users in Switzerland. Infect. 2005;33:273-7

18. Lloyd-Smith E, Hull MW, Tyndall MW, Zhang R, Wood E, Montaner JS, Kerr T, Romney MG. Community-associated methicillin-resistant Staphylococcus aureus is prevalent in wounds of community-based injection drug users. Epidemiol Infect. 2010;138:713-20.

19. Lee CH, Tsai CY, Li CC, Chien CC, Liu JW. Teicoplanin therapy for MRSA bacteraemia: a retrospective study emphasizing the importance of maintenance dosing in improving clinical outcomes. J Antimicrob Chemother. 2015;70:257-63.

20. Svetitsky S, Leibovici L, Paul M. Comparative efficacy and safety of vancomycin versus teicoplanin: systematic review and meta-analysis. Antimicrob Agents Chemother. 2009;53:4069-79.

21. Wiedemann K, Schmid C, Hamm H, Wirbelauer J. Staphylococcal scalded skin syndrome in a very low birth weight premature infant. Z Geburtshilfe Neonatol. 2016:220:35-8.

22. Layer F, Sanchini A, Strommenger B, Cuny C, Breier AC, Proquitte H, Buhrer C, Schenkel K, Batzing-Feigenbaum J, Greutelaers B, et al. Molecular typing of toxic shock syndrome toxin-1-and enterotoxin A-producing methicillinsensitive Staphylococcus aureus isolates from an outbreak in a neonatal intensive care unit. Int J Med Microbiol. 2015;305:790-8.

23. Udo EE, Al-Bustan MA, Jacob LE, Chugh TD. Enterotoxin production by coagulase-negative staphylococci in restaurant workers from Kuwait City may be a potential cause of food poisoning. J Med Microbiol. 1999;48: 819-23.

24. Lin J, Wu C, Yan C, Ou Q, Lin D, Zhou J, Ye X, Yao Z. A prospective cohort study of Staphylococcus aureus and methicillin-resistant Staphylococcus aureus carriage in neonates: the role of maternal carriage and phenotypic and molecular characteristics. Infect Drug Resist. 2018;11:555-65.

25. Monecke $S$, Ehricht $R$, Slickers $P$, Wiese N, Jonas D. Intra-strain variability of methicillin-resistant Staphylococcus aureus strains ST228-MRSA-I and ST5MRSA-II. Eur J Clin Microbiol Infect Dis. 2009;28:1383-90.
26. Wu D, Li X, Yang Y, Zheng Y, Wang C, Deng L, Liu L, Li C, Shang Y, Zhao C, et al. Superantigen gene profiles and presence of exfoliative toxin genes in community-acquired meticillin-resistant Staphylococcus aureus isolated from Chinese children. J Med Microbiol. 2011;60:35-45.

27. Mediavilla JR, Chen L, Mathema B, Kreiswirth BN. Global epidemiology of community-associated methicillin resistant Staphylococcus aureus (CAMRSA). Curr Opin Microbiol. 2012;15:588-95.

28. Yu F, Li T, Huang X, Xie J, Xu Y, Tu J, Qin Z, Parsons C, Wang J, Hu L, Wang L. Virulence gene profiling and molecular characterization of hospitalacquired Staphylococcus aureus isolates associated with bloodstream infection. Diagn Microbiol Infect Dis. 2012;74:363-8.

29. Soge OO, No D, Michael KE, Dankoff J, Lane J, Vogel K, Smedley J, Roberts MC. Transmission of MDR MRSA between primates, their environment and personnel at a United States primate Centre. J Antimicrob Chemother. 2016; 71:2798-803.

30. Cuny C, Köck R, Witte W. Livestock associated MRSA (LA-MRSA) and its relevance for humans in Germany. Int J Med Microbiol. 2013;303:331-7.

31. Garcia-Graells C, Antoine J, Larsen J, Catry B, Skov R, Denis O. Livestock veterinarians at high risk of acquiring methicillin-resistant Staphylococcus aureus ST398. Epidemiol Infect. 2011;140:383-9.

32. Huang SS, Singh R, McKinnell JA, Park S, Gombosev A, Eells SJ, Gillen DL, Kim D, Rashid S, Macias-Gil R, et al. Decolonization to reduce Postdischarge infection risk among MRSA carriers. N Engl J Med. 2019;380:638-50.

\section{Publisher's Note}

Springer Nature remains neutral with regard to jurisdictional claims in published maps and institutional affiliations.
Ready to submit your research? Choose BMC and benefit from:

- fast, convenient online submission

- thorough peer review by experienced researchers in your field

- rapid publication on acceptance

- support for research data, including large and complex data types

- gold Open Access which fosters wider collaboration and increased citations

- maximum visibility for your research: over $100 \mathrm{M}$ website views per year

At BMC, research is always in progress.

Learn more biomedcentral.com/submissions 